\title{
Cues used by Predators to Detect Freshwater Turtle Nests may Persist Late into Incubation
}

\author{
Julia L. RiLeY ${ }^{1}$ and JACQueline D. LitzGus ${ }^{1,2}$ \\ ${ }^{1}$ Department of Biology, Laurentian University, 935 Ramsey Lake Road, Sudbury, Ontario P3E 2C6 Canada \\ ${ }^{2}$ Corresponding author: jlitzgus@laurentian.ca
}

Riley, Julia L., and Jacqueline D. Litzgus. 2014. Cues used by predators to detect freshwater turtle nests may persist late into incubation. Canadian Field-Naturalist 128(2): 179-188.

Previous studies have found that turtle nest depredation is concentrated immediately post-oviposition, likely because cues alerting predators to nest presence are most obvious during this time. In Algonquin Provincial Park, Ontario, we examined the frequency of nest depredation during the incubation period for Snapping Turtles (Chelydra serpentina [Linnaeus, 1758]) and Midland Painted Turtles (Chrysemys picta marginata [Agassiz, 1857]). Contrary to most past findings, nest depredation occurred throughout the incubation period for both species. In fact, $83 \%$ and $86 \%$ of depredation interactions with Snapping and Painted Turtle nests, respectively, occurred more than a week after oviposition at our study site. Peaks in nest depredation (weeks with $\geq 10 \%$ nest depredation) occurred late in incubation and may have coincided with hatching. Trail cameras deployed at four nesting sites revealed six predator species interacting with nests. The presence of predators at nest sites increased late in the incubation period indicating a persistence or renewal (from hatching) of cues; additional research is necessary to determine the nature of these cues. These findings have implications for both research and turtle conservation. Further research should examine the relationship between temporal changes in predator species' density and patterns of nest depredation. Additionally, in areas where protective nest caging is used as a species recovery action, it may be important to ensure that cages remain in place throughout the incubation period until emergence of hatchlings.

Key Words: Snapping Turtles; Chelydra serpentina; Midland Painted Turtles; Chrysemys picta marginata; Turtles; Algonquin Provincial Park; Ontario; ecology; nest depredation; predator detection; predators; species recovery

\section{Introduction}

Freshwater and marine turtles are among the most atrisk groups of vertebrate animals, and one of the many threats to turtle populations is unnaturally high levels of nest predation (Gibbons et al. 2000; Spotila 2011). A broad range of animals from multiple taxa depredate turtle nests, including mammals, birds, reptiles, and invertebrates (Ernst and Lovich 2009). High levels of turtle nest depredation commonly occur in humandisturbed landscapes because food resources associated with human presence (e.g., trash, agricultural crops) increase the abundance of subsidized predators of turtle eggs (Christiansen and Gallaway 1984; Garber and Burger 1995; Mitchell and Klemens 2000; Seburn 2007; Fordham et al. 2008; Kurz et al. 2011). In addition, the removal of top predators in urban areas has caused an increase in the number of mesopredators, leading to a concomitant increase in depredation of turtle eggs (Barton 2003; Prugh et al. 2009; Ritchie and Johnson 2009). In some turtle populations, subsidized mesopredators annually depredate $100 \%$ of nests (e.g., Geller 2012), resulting in chronic prevention of recruitment (Spinks et al. 2003; Seburn 2007; Fordham et al. 2008). Substantial repeated reductions in recruitment (approximately a $50 \%$ or more decrease in egg and/or hatchling survival) perpetuate population declines (Crouse et al. 1987; Crowder et al. 1994; Tomillo et al. 2008). World-wide and in Canada, turtle populations are in decline (Gibbons et al. 2000); thus, it is important to understand all possible threats, including the ecology and behaviour of nest predators, to increase the effectiveness of management and recovery actions.
Many studies of turtle nest depredation report that most depredation events occur within the first week post-oviposition (Tinkle et al. 1981; Christens and Bider 1987; Congdon et al. 1983, 1987; Robinson and Bider 1988; Burke et al. 2005; Strickland et al. 2010; Geller 2012; Wirsing et al. 2012; Holcomb and Carr 2013). For example, Congdon et al. (1983) found that $87 \%$ of Blanding's Turtle (Emydoidea blandingii) nest depredation occurred within the first 5 days post-oviposition. Congdon et al. (1987) found that of depredated Snapping Turtle (Chelydra serpentina) nests, 59\% were depredated within the first $24 \mathrm{~h}, 73 \%$ of these nests were depredated within the first 6 days, and $100 \%$ by the $32^{\text {nd }}$ day post-oviposition. Robinson and Bider (1988) found that $57 \%$ of depredation events occurred within $72 \mathrm{~h}$ of nest construction, and $87 \%$ occurred within 5 days post-oviposition. Similarly, Desroches and Picard (2007) found that $80 \%$ of nests were depredated in the first week post-oviposition. Holcomb and Carr (2013) found that $86 \%$ of Alligator Snapping Turtle (Macrochelys temminckii) nests were depredated within the first $24 \mathrm{~h}$, and, on average, the time until depredation was $19 \mathrm{~h}$.

The high peak of depredation immediately postoviposition is thought to occur because cues alerting predators to the presence of a nest are most prominent at this time. These cues might include olfactory stimuli, such as the scent of oviposition fluid (Legler 1954; Congdon et al. 1983; Spencer 2002), and visual cues, such as the presence of a female turtle (Congdon et al. 1987; Eckrich and Owens 1995) and soil disturbance 
(Strickland et al. 2010; Spencer 2002). Acceptance of this evidence has led some researchers examining cues for nest depredation (e.g., Marchand and Livaitis 2004; Strickland et al. 2010) to base their methodology on the premise that depredation of turtle nests is restricted to the first week post-oviposition. For only 2 weeks, Marchand and Livaitis (2004) monitored fake nests constructed to investigate depredation, and Strickland et al. (2010) monitored nests for 2 days postoviposition. Yet, is an early peak the only temporal pattern of turtle nest depredation reported in the literature?

Although most studies of nest depredation report that it occurs within a short time post-oviposition, a few, largely neglected, studies document substantial levels of nest depredation throughout or late in the incubation period. Snow (1982) found that 55\% of depredated Painted Turtle (Chrysemys picta) nests were older than 3 days; however, all of the nests were still depredated within the first month of incubation. Brooks et al. (1992) found that all Wood Turtle (Glyptemys insculpta) nest depredation occurred 9 weeks after the last nest was laid. Burger (1977) found that the risk of depredation of Diamond-backed Terrapin (Malaclemys terrapin) nests did not decrease over the course of incubation; instead, nest depredation was significantly higher $60-90$ days post-oviposition (75\% of remaining nests depredated) than 1-30 days and 30-60 days post-oviposition $(27 \%$ and $20 \%$ of nests within those periods, respectively). Gillingwater (2002) observed nest predation throughout the incubation period and, in some cases, Northern Map Turtle (Graptemys geographica) nests were depredated the following spring after hatchlings had overwintered in the nest. Some reports document bimodal predator activity, with peaks around nesting and hatching. For example, Congdon et al. (1983) found that a few nests $(6 \%)$ were depredated at the end of the incubation period during hatchling emergence and, similarly, Desroches and Picard (2007) found that $5 \%$ of freshwater turtle nests were depredated during hatchling emergence. In these studies, because of a large peak in nest depredation immediately post-oviposition, there may not have been many nests left to depredate in the fall. Also, nest debris may make nest-searching by predators more challenging.

Nevertheless, predators often appear to cue in on nests later in incubation. During fieldwork for a 41year study of the ecology of Snapping Turtles and a 35-year study of Midland Painted Turtles (Chrysemys picta marginata) based out of the Wildlife Research Station (WRS, $45^{\circ} 35^{\prime} \mathrm{N}, 78^{\circ} 30^{\prime} \mathrm{W}$ ) in Algonquin Provincial Park, Ontario (R. J. Brooks, University of Guelph and J. D. Litzgus, Laurentian University), field technicians observed that nest depredation was occurring throughout incubation. These observations and our subsequent review of the literature led to our research question: do predators detect nest cues that persist long after oviposition and lead to later occurrences of nest depredation?
In the long-term Algonquin Park study, eggs are removed from the nest cavity less than $4 \mathrm{~h}$ post-oviposition, measured, and reburied within $24 \mathrm{~h}$ (Samson et al. 2007). This study method is common in turtle research, management, and conservation programs globally; thus, depredation patterns documented in our study may be representative of what is occurring under these circumstances. This method also provides the unique opportunity to examine the temporal pattern of nest depredation that occurs when fresh cues left by the mother are reduced. The aim of our project was two-fold: first, to quantify the frequency of nest depredation throughout incubation for Snapping and Midland Painted Turtles when nest cues are reduced immediately post-oviposition and, second, to compare this temporal pattern to patterns reported previously to determine if nest cues and depredation peaks are present later in incubation.

\section{Study Area}

The study took place along the Highway 60 corridor on the west side of Algonquin Provincial Park, Ontario, Canada. The study area is within the Algonquin-Lake Nipissing ecoregion, which is a rugged landscape underlain by Precambrian Shield outcrops (Ontario Ministry of Natural Resources 1998). Forest cover dominates, with predominantly upland mixed forests of sugar maple (Acer saccharum), yellow birch (Betula alleghaniensis), and eastern hemlock (Tsuga canadensis) and lowland sites with spruce (Picea spp.) and tamarack (Larix laricina) (Hughes 2003). Field sampling was concentrated at two sites: the WRS and Arowhon. The WRS is within the North Madawaska watershed and nesting sites in this area vary from natural sand dunes beside lakes to gravel embankments along access roads and Highway 60. At the Arowhon site, nesting occurs on a decommissioned rail-line that is used as a public hiking trail (Mizzy Lake Trail; Schwarzkopf and Brooks 1985). Elevations on the west side of Algonquin Park (370 - $570 \mathrm{~m}$ above sea level) are higher than the surrounding landscape and experience a cool and wet climate (Ontario Ministry of Natural Resources 1998); this climate is reflective of the northern range limits of both turtle species.

\section{Methods}

From 30 May to 4 July 2011, Snapping and Midland Painted Turtle nesting was monitored daily. Nest sites were monitored visually by researchers on foot and using binoculars. Monitoring occurred from dawn (about 0500) to about 1000, and from just before to dusk (about 1700) until after dark, as long as nesting activity was occurring, to capture the time frames in which Snapping and Painted Turtles experience peak nesting (Ernst and Lovich 2009). The nesting activity of each female was recorded as it occurred. Nest locations were marked with metal stakes and flagging tape. Nests were carefully excavated, maintaining the eggs 
in the same order and orientation in which they were found (Samson et al. 2007). After the eggs were removed, the nest cavities were filled with soil excavated during egg removal. The eggs were taken to a field laboratory to record clutch data for the long-term study (egg data were not used in the current study). Eggs were reburied in their original nest chambers within $24 \mathrm{~h}$ post-oviposition, before the vitelline membrane adhered to the inner shell surface and formed a "white spot" on the top of the egg (Yntema 1964; Rafferty and Reina 2012), thus ensuring no trauma to developing embryos (Samson et al. 2007). We cannot discount the possibility that removal, processing, and reburial of eggs by researchers in the first $24 \mathrm{~h}$ affected depredation rates, especially at the start of incubation. Although we present data for the first $72 \mathrm{~h}$ post-oviposition, we are aware they may not be indicative of depredation rates on nests from which eggs were not removed (Congdon et al. 1983; Tinkle et al. 1981; Christens and Bider 1987; Burke et al. 2005; Strickland et al. 2010; Geller 2012; Wirsing et al. 2012).
Each nest was randomly assigned to a caging treatment (above ground, below ground, or wooden-sided cage, or uncaged control) and cages were deployed when the eggs were reburied (69 Midland Painted Turtle and 52 Snapping Turtle nests). Various nest cage types were used to test their effects on hatchling fitness for another study (Riley and Litzgus 2013); here we report only the details of predator interactions with these nests. During the nesting season (June) and the hatching season (September), the nests were monitored daily for predation attempts and successful depredation events. During the remainder of the incubation period (July and August), the nests were monitored weekly (Burke et al. 1998; Kolbe and Janzen 2002) because of logistic constraints. A depredation attempt was recorded when substrate was cleared away from around the nest or nest cage and/or the nest cage was dug up but the predator did not reach the nest chamber (Figure 1A). A successful depredation event was recorded when eggs were dug up and/or eaten (Figure $1 \mathrm{~B})$. If predator tracks and scat were discernible

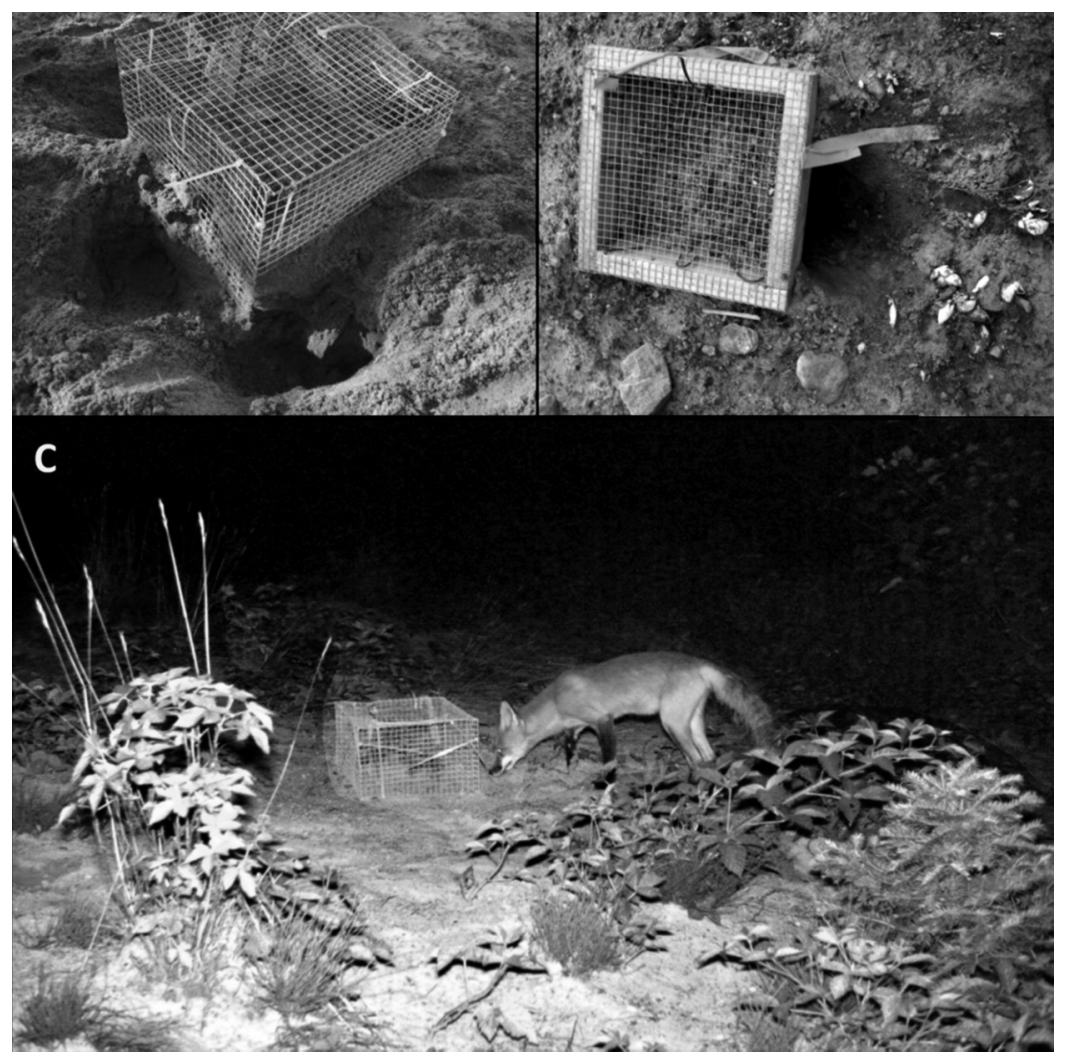

FiguRE 1. A. An above-ground nest cage with substrate cleared away from the sides indicating a depredation attempt. B. Successful depredation of a nest protected by a wooden-sided cage indicated by the excavated nest chamber and eggshell fragments. C. A trail camera photograph of a Red Fox (Vulpes vulpes) interacting with a nest outfitted with an aboveground cage. All photographs were taken during summer 2011 in Algonquin Provincial Park, Ontario, Canada. 
around a nest, the predator species was identified and recorded. To gauge the predator assemblage patrolling the nesting sites and to capture interactions between predators and nest cages, four trail cameras (119456C, Bushnell Corporation, Overland Park, Kansas, USA) were set-up from 1 July to 1 October 2011 at four nest sites.

The numbers of depredation attempts and successful depredation events were combined for analysis to create a total number of depredation interactions. This total did not differ among cage types or from the uncaged control nests over the incubation period (Riley and Litzgus 2013). It was assumed that if the nest cages were not protecting the clutches, a depredation attempt would have been successful. If a nest was subject to multiple depredation attempts (i.e., a predator targeted the same nest multiple times), only the first attempt was included in the dataset.

We quantified predator interactions with nests in two ways. First, we used a non-parametric product-limit survival analysis (Kaplan and Meir 1958; Engeman et al. 2006). The survival time equaled the time (days) from oviposition to the first predator interaction. When eggs hatched, those nests were considered "censored" after the time of that event, and thus removed from the analysis. A Mann-Whitney-Wilcoxon test was used to compare the survival curves between species. Second, we undertook a more detailed analysis of the specific timing of the depredation interactions during incubation. This part of the analysis included only nests that were subject to depredation interactions during incubation (Snapping Turtle, 29/52 nests; Midland Painted Turtle, 28/69 nests). For each species, the number of depredation interactions was totaled for each week of incubation (29 May to 1 October 2011). This number was divided by the total number of depredation interactions over the incubation period and multiplied by 100 to calculate the percentage (i.e., frequency) of depredation interactions that occurred weekly. For each species, this observed distribution of depredation fre- quency was compared with an expected distribution based on previous quantified reports of depredation in the literature, using a Kolmogorov-Smirnov goodnessof-fit test. From all literature sources that contained usable data, we averaged the reported data to generate an expected distribution of depredation interactions by week post-oviposition (Table 1). Also, using a Kolmogorov-Smirnov goodness-of-fit test and our data, we compared the distribution of weekly depredation interactions post-oviposition for Snapping Turtles with that for Midland Painted Turtles to determine whether there were differences in pattern. Depredation peaks were identified as weeks with $\geq 10 \%$ nest depredation. A significance level of $\alpha=0.05$ was used for all statistical tests. Statistical analyses were performed using R (R Foundation for Statistical Computing, Vienna, Austria).

For predator interactions where tracks or scat were identified, the number of interactions observed for each predator species was summarized monthly. Similarly, the number of photographs of each predator species taken by the trail cameras was summarized monthly to elucidate temporal patterns of predator presence at the nest sites over the course of incubation.

\section{Results}

For both turtle species, the probability of nest survival decreased steadily with number of days postoviposition (Figure 2). The survival curves did not differ between species $\left(W_{1}=365, P=0.11\right)$. In 2011, the first Snapping Turtle nest was found on 7 June, and the last nest was found on 24 June. The observed frequency of weekly predator interactions with Snapping Turtle nests over the incubation period was different than the expected distribution of depredation interactions post-oviposition $(D=0.63, P<0.01$; Figure $3 \mathrm{~A})$. For Midland Painted Turtles, the first nest was found on 2 June and the last was found on 2 July. The observed frequency of weekly predator interactions with Midland Painted Turtle nests over the incubation period

TABLE 1. Rates of turtle nest predation over the course of incubation reported in previously-published studies. The means of these rates were used to create an "expected distribution" of depredation frequencies for comparison with our observed frequencies for Snapping Turtles and Midland Painted Turtles in Algonquin Provincial Park using a Kolmogorov-Smirnov goodness-of-fit test. For the purposes of the test, the mean depredation frequency estimated for weeks $4+(3.7 \%)$ was split over weeks $4-16(0.3 \%$ each week).

\begin{tabular}{|c|c|c|c|c|c|}
\hline \multirow[b]{2}{*}{ Study } & \multirow[b]{2}{*}{ Species } & \multicolumn{4}{|c|}{ Depredation frequency $(\%)$} \\
\hline & & Week 1 & Week 2 & Week 3 & Week 4+ \\
\hline Congdon et al. 1983 & Blanding's Turtle & 87 & 5 & 4 & 4 \\
\hline Christens and Bider 1987 & Painted Turtle & 86 & 0 & 0 & 14 \\
\hline Burke et al. 2005 & Diamond-backed Terrapin & 100 & 0 & 0 & 0 \\
\hline \multirow{2}{*}{ Wirsing et al. 2012} & Snapping Turtle & 98 & 1 & 0 & 1 \\
\hline & Painted Turtle & 98 & 1 & 0 & 1 \\
\hline Geller 2012 & Map Turtle spp. & 90 & 7 & 0 & 3 \\
\hline Snow 1982 & Painted Turtle & 64 & 21 & 12 & 3 \\
\hline $\begin{array}{l}\text { Mean expected distribution used } \\
\text { in Kolmogorov-Smirnov test }\end{array}$ & & 89 & 5 & 2.3 & 3.7 \\
\hline
\end{tabular}



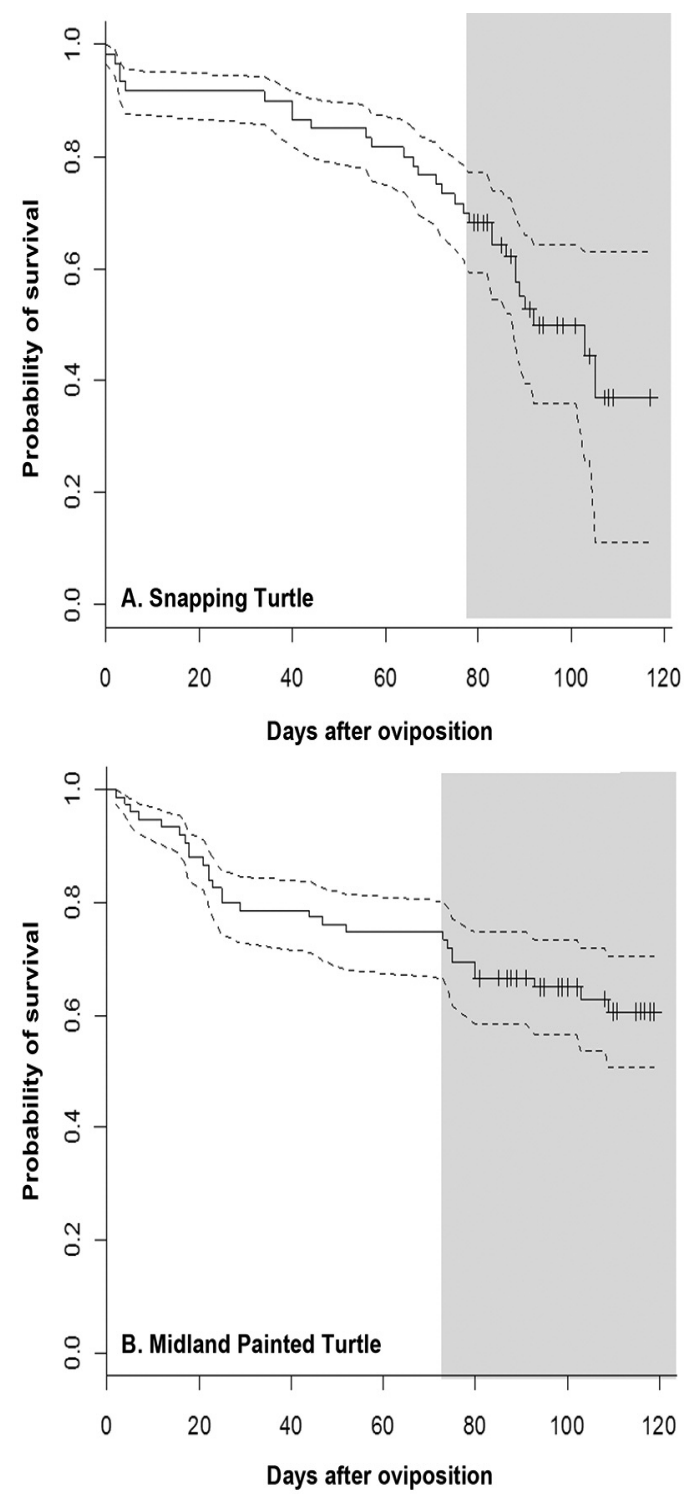

FIGURE 2. Survival curves (solid lines) for (A) Snapping Turtle (Chelydra serpentina) and (B) Midland Painted Turtle (Chrysemys picta marginata) nests over the incubation period in Algonquin Provincial Park. Vertical tick marks indicate when eggs hatched and their nest was "censored" from the analysis. The grey area represents the period when hatchlings were emerging from the nests. Dashed lines indicate standard errors.

was also different from the expected distribution $(D$ $=0.63, P<0.01$; Figure 3B).

For Snapping Turtle nests, $17 \%$ of predator interactions occurred in the first week post-oviposition. Another peak of predator interactions (weekly interactions ranging from $10 \%$ to $17 \%$ of the total depredation interactions) occurred from weeks 10 to 14 (64 to
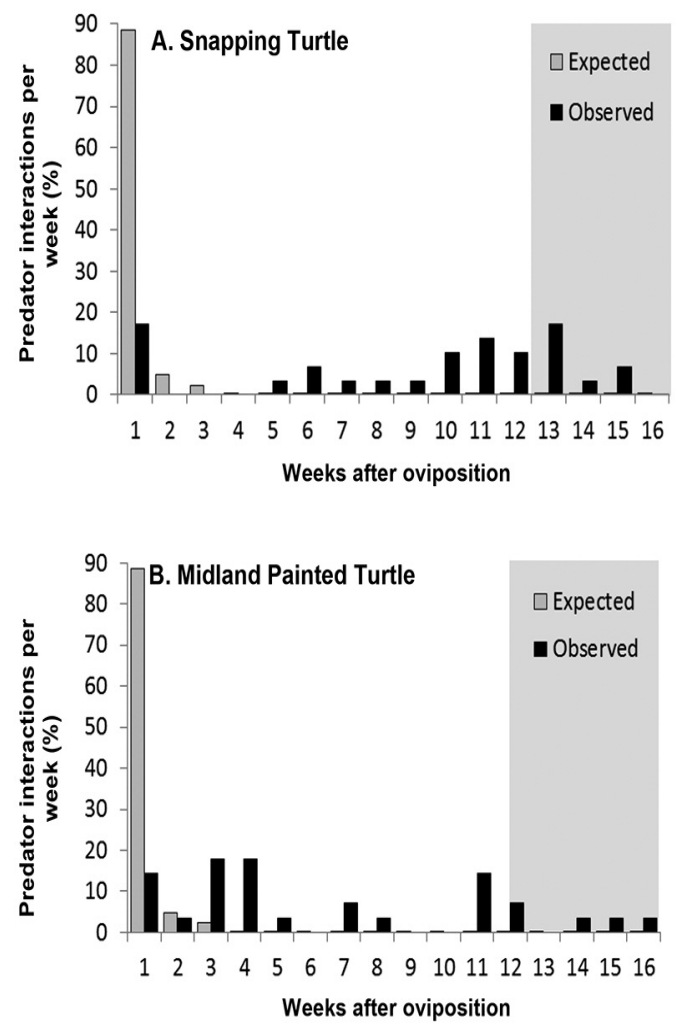

FIgURE 3. For (A) Snapping Turtle (Chelydra serpentina) and (B) Midland Painted Turtle (Chrysemys picta marginata) nests in Algonquin Provincial Park, observed weekly frequencies of predator interactions over the incubation period (29 May to 17 September 2011) were significantly different from those expected based on previous reports (see Table 1 for list of studies). The grey area represents the period when hatchlings were emerging from the nests.

91 days) post-oviposition. Predator interactions occurred throughout the incubation period up to 105 days post-oviposition. For Midland Painted Turtle nests, $14 \%$ of predator interactions occurred in the first week post-oviposition. Another spike in predator interactions occurred 3 and 4 weeks post-oviposition, when $18 \%$ of total depredation interactions occurred each week. Another peak in depredation occurred at 11 weeks (7177 days) post-oviposition, when $14 \%$ of total depredation interactions occurred. We also observed elevated levels of predation in week 12 ( $7 \%$ of total depredation interactions). Similar to Snapping Turtle nests, predator interactions with Midland Painted Turtle nests occurred throughout incubation until 109 days postoviposition. The number of predator interactions per week over the incubation period did not differ between species $(D=0.31, P=0.42)$.

Six predator species were identified interacting with nests and were present at the study sites throughout 
incubation: Red Fox (Vulpes vulpes), Eastern Wolf (Canis lycaon), Raccoon (Procyon lotor), American Crow (Corvus brachyrhynchos), Common Raven (Corvus corax), and Wild Turkey (Meleagris gallopa$v o$ ) (Figure 4). The number of photographs of predators at nest sites captured by the trail cameras was high- est in August and September; specifically, the number of photographs of canid (Red Fox and Eastern Wolf) predators increased during this time. Of the predator interactions for which species were identified, Red Foxes were the most common predators of nests from July until the end of incubation.
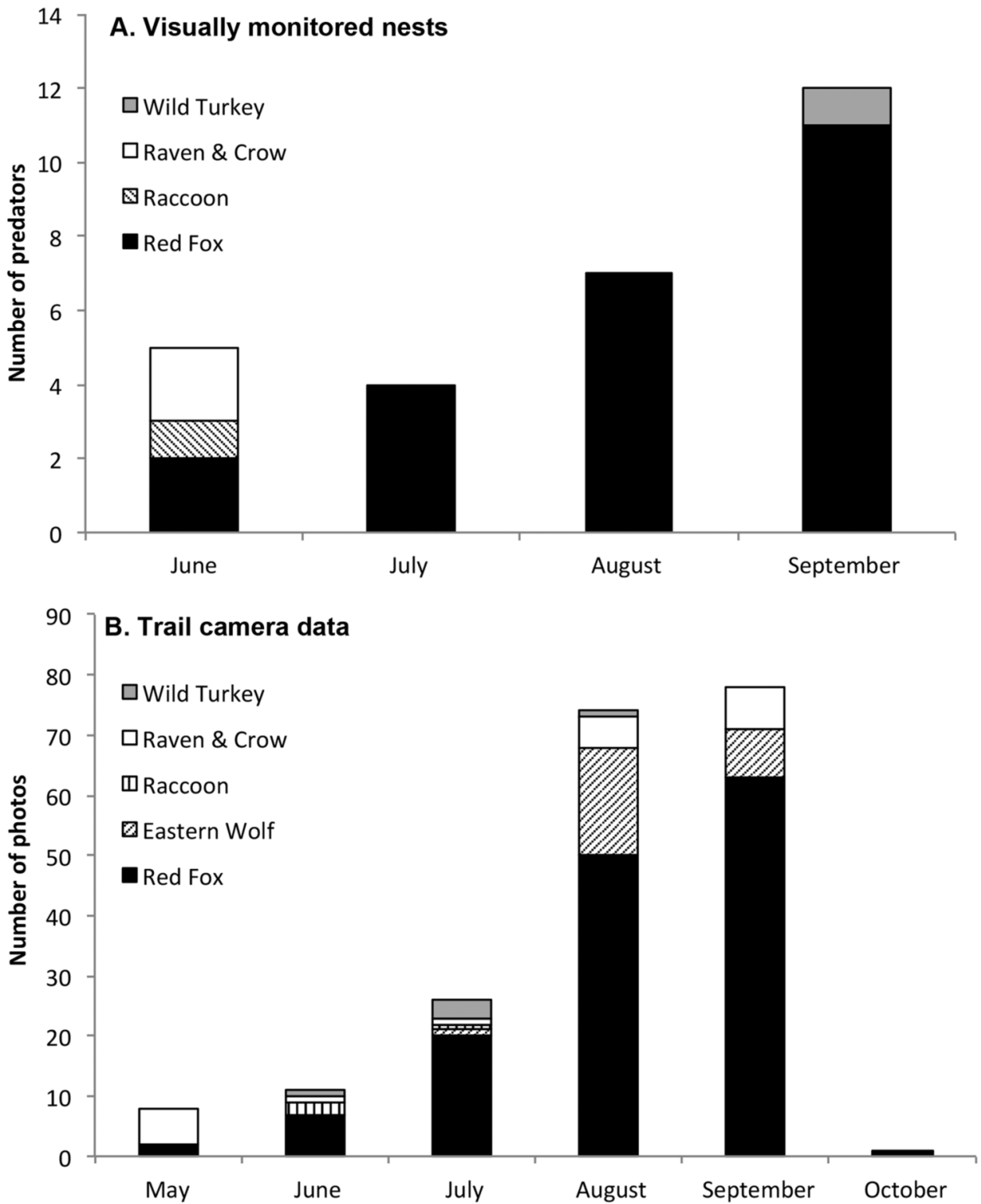

Figure 4. Assessment of the predator assemblage at Snapping Turtle (Chelydra serpentina) and Midland Painted Turtle (Chrysemys picta marginata) nesting sites in Algonquin Provincial Park by (A) number of predators identified from tracks and scat interacting with nests and (B) number of photographs taken by trail cameras of each predator species by month over the incubation period. 


\section{Discussion}

We observed nest predation throughout incubation, and there were peaks in depredation (one for Snapping Turtles and two for Midland Painted Turtles) more than a week after oviposition. Our observed patterns of nest predation were atypical compared to those generally reported in the literature. Only a handful of other published studies have reported nest predation throughout or late in incubation (Snow 1982; Burger 1977). Also, the presence of predators at nest sites in our study, particularly canid species, increased later in incubation (August and September). These later peaks in depredation may be a result of a larger predator population at this time of year because canid pups begin to hunt independently in the fall (C. Callaghan pers. comm.), and because predators are somehow cueing to nests at hatching. Wild dogs have been documented to target Leatherback Sea Turtle (Dermochelys coriacea) and Green Sea Turtle (Chelonia mydas) nests during hatching and to dig up nests and prey on hatchlings before their emergence from the nest (Spotila 2011). Burger (1977) found that crows and gulls depredated terrapin nests only during oviposition, whereas mammals (raccoons and foxes) depredated nests at a low rate during oviposition and at a high rate during hatching. Also, mammalian predators depredated Wood Turtle (Glyptemys insculpta) nests 9 weeks post-oviposition (Brooks et al. 1992). In our study, removing eggs from nests in the first $24 \mathrm{~h}$ post-oviposition (which may have reduced early-incubation nest depredation) provided an opportunity to investigate depredation in the later stages of incubation.

It appears that cues to nests exist and can be detected by predators throughout egg incubation, but what are these cues? The most obvious answer may be that the predator-exclusion cages around several of the nests monitored in our study may have served as visual cues to the nests' presence. However, our study also included nests with no cages and nests protected by cages that did not extend above ground (Riley and Litzgus 2013) and, therefore, did not provide a visual cue. Indeed, predation interactions did not differ among the nest caging treatments, including controls with no cages (Riley and Litzgus 2013); thus, it does not appear that predators were using nest cages as visual cues to a food source. Other researchers have also found that marking nests did not increase depredation rates (Burke et al. 2005; Strickland et al. 2010). In contrast, raccoons, coyotes, and Corvus sp. have been found to use nest cages and nest markers, respectively, as visual cues for nests (Mroziak et al. 2000; Rollinson and Brooks 2007; S. D. Gillingwater, pers. comm.). This is most likely a learned response (Rollinson and Brooks 2007), and it appears that, at our study site, predators have not yet learned to associate nest cages, which were present for only 2 summers, with the presence of turtle eggs.

A few other studies that examined unprotected turtle nests also found that nest predation occurred late in incubation (Snow 1982; Burger 1977; Brooks et al. 1992); thus, a natural cue must be attracting predators to nests at that time. For Midland Painted Turtles, the depredation peak at 3-4 weeks post-oviposition could be associated with predators returning to the nesting sites when these turtles lay their second clutches (approximately 2 weeks after the first clutch is deposited at our study sites; Brooks et al., unpublished data). The return of nesting female turtles may present a visual cue for predators. The presence of hatchlings at a nesting site may also act as a visual cue for predators later on in incubation and trigger further searching and predation of nests. At Rondeau Provincial Park and Long Point, Ontario, raccoons and coyotes have been observed following the tracks of early-emerging turtles back to their natal nest and consuming the remaining eggs and young (S. D. Gillingwater, pers. comm.).

How else would predators know where unmarked turtle nests are located? Embryonic fluids released during hatching could serve as olfactory cues to attract predators to nests in August and September. In addition, rotting undeveloped or unfertilized eggs may produce olfactory cues. At our study sites, canid presence increased in August and September, and this group of animals is well-known for its outstanding olfactory abilities (Spotila 2011). Another possibility for nest detection may be auditory cues. Some turtle hatchlings have recently been reported to vocalize within the nest cavity after hatching (Ferrara et al. 2013).

In our study, the later peak in predator interactions with nests was found at 64-94 and 71-77 days postoviposition for Snapping and Painted Turtles, respectively. These peaks of depredation precede the beginning of hatchling emergence for Snapping Turtles (77 days post-emergence; Riley et al. unpublished data) by 13 days, and for Midland Painted Turtles (74 days post-emergence; Riley et al. unpublished data) by 3 days. Thus, these peaks could correspond to the release of embryonic fluids (olfactory cues) and potential vocalization by hatchlings (auditory cues). The study by Brooks et al. (1992) lends support to this idea, as mammalian predators began depredating nests at their study site 9 weeks after the last nest was completed, which corresponds to the hatching period and hatchling emergence for Wood Turtles (Ernst and Lovich 2009). Although this is a convincing association, it is impossible to correlate definitively the later peak in predator interactions with the hatching period from our study alone, as it is unknown when the eggs were hatching. Hatchlings often remain in the nest chamber after hatching, sometimes emerging 1-9 days later (Burger 1976; Christens 1990) or, in the case of Painted Turtles, in the spring after overwintering in the nest (Storey et al. 1988; Costanzo and Lee 1995; Costanzo et al. 2000; Packard and Packard 2003, 2004). Future work should examine olfactory, auditory, and visual cues at nests throughout incubation to determine whether the presence or types of cues change with time. 
In our study, given that we potentially changed the nest cues during the first $24 \mathrm{~h}$ post-oviposition, we were able to measure peaks in nest depredation later in incubation for two freshwater turtle species. For Snapping Turtles, there was a later peak in nest depredation 10-14 weeks post-oviposition, and, for Midland Painted Turtles, there were peaks in nest depredation during weeks 3,4 , and 11 post-oviposition. There was also an increase in the number of canid predators at the study sites during these later peaks in incubation, which corroborates the findings of other studies in which mammal predator presence at nest sites increased before hatchling emergence from nests (Spotila 2011; Burger 1977). We report that there were comparatively low peaks in nest predation during the first week post-oviposition: only $17 \%$ and $14 \%$ of depredation interactions with Snapping and Midland Painted Turtle nests, respectively, occurred at this time. Some researchers have observed similar trends at other study sites, with nest predation occurring both during nesting and hatchling emergence (Burger 1977; Spotila 2011; Congdon et al. 1983; Desroches and Picard 2007). At various sites, differences in predator species densities and interspecific differences in the cues used by predators to find nests (i.e., avian species using visual cues, and mammal species using visual and olfactory cues) may be responsible for geographic variation in depredation frequency over incubation. Depredation frequency may also depend on individual predator behaviours and how they vary among sites. More research is needed to examine the effects of predator species and predator behaviour on temporal patterns of nest predation.

Management of at-risk turtles throughout North America commonly includes the use of cages to protect nests from subsidized mesopredators (Seburn 2007; Riley and Litzgus 2013). Some strategies suggest removal of nest cages halfway through incubation, as it is thought that depredation will not occur during the last half of incubation. In a study by Rahman and Burke (2010), nest protectors were removed from nests after 21-25 days of incubation, and, in one study area (out of three), depredation significantly increased in the 11 nights after nest protector removal. Engeman et al. (2006) also found that after removing nest cages from sea turtle nests, depredation rates increased substantially. Soil disturbance during nest cage removal may provide a cue to attract predators (Rahman and Burke 2010). An alternative to removing nest cages partway through incubation is including an opportunity for turtles to escape from the cage (e.g., escape hatches or holes). Our study, as well as others that document nest depredation before hatchling emergence, indicates that turtle nests can be at risk of depredation throughout the full incubation period. Thus, it is important to understand and study depredation timing at each location, as it may be site or predator specific, to gauge the effectiveness of a particular nest protection method for that site. In some areas, species recovery may re- quire that nest protection measures remain in place throughout incubation and extend to hatchling emergence.

\section{Acknowledgements}

All work was carried out in compliance with the Canadian Council for Animal Care guidelines and under approved Laurentian University Animal Care Committee protocol 2008-12-02. All work was authorized by permits from the Ontario Ministry of Natural Resources (OMNR). Financial support for this work was provided by the Natural Sciences and Engineering Research Council, the Canadian Wildlife Federation, the OMNR's Species at Risk Stewardship Fund, the Toronto Zoo, and Laurentian University. In-kind contributions were provided by the Wildlife Research Station (WRS) in Algonquin Provincial Park and the University of Guelph. We thank R. J. Brooks for allowing access to his long-term study sites. Thanks also to the following people who assisted with fieldwork: $\mathrm{K}$. Hall, M. Keevil, H. McCurdy-Adams, P. Moldowan, L. Monck-Whipp and staff and volunteers from the WRS. Thanks to J. Baxter-Gilbert, C. Davy, P. Moldowan, S. Gillingwater, and an anonymous reviewer for their helpful comments on the manuscript.

\section{Literature Cited}

Barton, B. T. 2003. Cascading effects of predator removal on the ecology of sea turtle nesting beaches. M.Sc. thesis, University of Central Florida, Orlando, Florida, USA.

Burger, J. 1976. Behavior of hatchling diamondback terrapins (Malaclemys terrapin) in the field. Copeia 1976: 742 748.

Burger, J. 1977. Determinants of hatching success in Diamondback Terrapin, Malaclemys terrapin. American Midland Naturalist 97: 444-464.

Burke, V. J., S. L. Rathbun, J. Bodie, and J. W. Gibbons. 1998. Effect of density on predation rate for turtle nests in a complex landscape. Oikos 83: 3-11.

Burke, R. L., C. M. Schneider, and M. T. Dolinger. 2005. Cues used by raccoons to find turtle nests: effects of flags, human scent and diamond-backed terrapin sign. Journal of Herpetology 39: 312-315.

Brooks, R. J., C. M. Shilton, G. P. Brown, and N. W. S. Quinn. 1992. Body size, age distribution, and reproduction in a northern population of wood turtles (Clemmys insculpta). Canadian Journal of Zoology 70: 462-469.

Christens, E. 1990. Nest emergence lag in loggerhead sea turtles. Journal of Herpetology 24: 400-402.

Christens, E., and J. R. Bider. 1987. Nesting activity and hatching success of the painted turtle (Chrysemys picta marginata) in Southwestern Quebec. Herpetologica 43: 55-65.

Christiansen, J. L., and B. J. Gallaway. 1984. Raccoon removal, nesting success, and hatchling emergence in Iowa turtles with special reference to Kinosternon flavescens. Southwestern Naturalist 29: 343-348.

Congdon, J. D., G. L. Breitenbach, R. C. van Loben Sels, and D. W. Tinkle. 1987. Reproduction and nesting ecology of snapping turtles (Chelydra serpentina) in Southeastern Michigan. Herpetologica 43: 39-54. 
Congdon, J. D., D. W. Tinkle, G. L. Breitenbach, R. C. and van Loben Sels. 1983. Nesting ecology and hatching success in the turtle Emydoidea blandingi. Herpetologica 39: 417-429.

Costanzo, J. P., and R. E. Lee, Jr. 1995. Supercooling and ice nucleation in vertebrates. Pages 221-237 in Biological Ice Nucleation and Its Applications. Edited by R. E. Lee, Jr., G. J. Warren, and L. V. Gusta. American Phytopathological Society, St. Paul, Minnesota, USA.

Costanzo, J. P., J. D. Litzgus, J. B. Iverson, and R. E. Lee, Jr. 2000. Seasonal changes in physiology and developments of cold hardiness in the hatchling painted turtle Chrysemys picta. Journal of Experimental Biology 203: 3459-3470.

Crouse, D. T., L. B. Crowder, and H. Caswell. 1987. A stagebased population model for loggerhead sea turtles and implications for conservation. Ecology 68: 1412-1423.

Crowder, L. B., D. T. Crouse, S. S. Heppell, and T. H. Martin. 1994. Predicting the impact of turtle excluder devices on loggerhead sea turtle populations. Ecological Applications 4: 437-445.

Desroches, J. R., and I., Picard. 2007. Évaluation de 1'impact des routes sur les population de tortues en Outaouais, Québec. Ministère des Transports du Québec, Québec, Québec, Canada.

Eckrich, C. E., and D. W. Owens. 1995. Solitary versus arribada nesting in the Olive Ridley Sea Turtles (Lepidochelys olivacea): a test of the predator-satiation hypothesis. Herpetologica 51: 349-354.

Engeman, R. M., R. E. Martins, H. T. Smith, J. Woolard, and C. K. Crady. 2006. Impact on predation of sea turtle nests when predator control was removed halfway through the nesting season. Wildlife Research 33: 187-192.

Ernst, C. H., and J. E. Lovich. 2009. Turtles of the United States and Canada. Second edition. Johns Hopkins University Press, Baltimore, Maryland, USA

Ferrara, C. R., R. C. Vogt, and R. S. Sousa-Lima. 2013. Turtle vocalizations as the first evidence of post-hatching parental care in chelonians. Journal of Comparative Psychology 127: 24-32.

Fordham, D. A., A. Georges, and B. W. Brook. 2008. Indigenous harvest, exotic pig predation and location persistence of a long-lived vertebrate: managing a tropical freshwater turtle for sustainability and conservation. Journal of Applied Ecology 45: 52-62.

Garber, S. D., and J. Burger. 1995. A 20-yr study documenting the relationship between turtle decline and human recreation. Ecological Applications 5: 1151-1162.

Geller, G. A. 2012. Notes on the nest predation dynamics of Graptemys at two Wisconsin sites using trail camera monitoring. Chelonian Conservation and Biology 11: 197-205.

Gibbons, J. W., D. E. Scott, T. J. Ryan, K. A. Buhlmann, T. D. Tuberville, B. S. Metts, J. L. Greene, T. Mills, Y. Leiden, S. Poppy, and C. T. Winne. 2000. The global decline of reptiles, déjà vu amphibians. Bioscience 50 653-666.

Gillingwater, S. D. 2002. A selective herpetofaunal survey, inventory and biological research study of Rondeau Provincial Park. Report to Rondeau Provincial Park. Morpeth, Ontario.

Holcomb, S. R., and J. L. Carr. Mammalian depredation of artificial alligator snapping turtle (Macrochelys temminckii) nests in north Louisiana. Southeastern Naturalist 12: 478-491.
Hughes, E. J. 2003. Nest-site selection, hatching success and hatchling over-winter success in painted turtles (Chrysemys picta). M.Sc. thesis, University of Guelph, Guelph, Ontario.

Kaplan, E. L., and P. Meir. 1958. Nonparametric estimation from incomplete observations. Journal of the American Statistical Association 53: 457-481.

Kolbe, J. J., and F. J. Janzen. 2002. Spatial and temporal dynamic of turtle nest predation: edge effects. Oikos 99: 538-544.

Kurz, D. J., K. M. Straley, and B. A. DeGregorio. 2011. Out-foxing the red fox: how to best protect the nests of the endangered loggerhead marine turtle Caretta caretta from mammalian predation? Oryx 2011: 1-6.

Legler, J. M. 1954. Nesting habits of the western painted turtle, Chrysemys picta belli (Gray). Herpetologica 10: 137144.

Marchand, M. N., and J. A. Litvaitis. 2004. Effects of landscape composition, habitat features, and nest distribution on predation rates of simulated turtle nests. Biological Conservation 117: 243-251.

Mitchell, J. C., and M. W. Klemens. 2000. Primary and secondary effects of habitat alteration. Pages 5-32 in Turtle Conservation. Edited by M. W. Klemens. Smithsonian Institution Press, Washington, DC, USA.

Mroziak, M. I., M. Salmon, and K. Rusenko. 2000. Do wire cages protect sea turtles from foot traffic and mammalian predators? Chelonian Conservation and Biology 3 : 693-698.

Ontario Ministry of Natural Resources. 1998. Algonquin Provincial Park management plan. Ottawa: Queen's Printer for Ontario.

Packard, G. C., and M. J. Packard. 2003. Natural freezetolerance in hatchling painted turtles? Comparative Biochemistry and Physiology 134: 233-246.

Packard, G. C., and M. J. Packard. 2004. To freeze or not to freeze: adaptations for overwintering by hatchlings of the North American painted turtle. Journal of Experimental Biology 207: 2897-2906.

Prugh, L. R., C. J. Stoner, C. W. Epps, W. T. Bean, W. J. Ripple, A. S. Laliberte, and J. S. Brashares. 2009. The rise of the mesopredator. BioScience 59: 779-791.

Rafferty, A. R., and R. D. Reina. 2012. Arrested embryonic development: a review of strategies to delay hatching in egg-laying reptiles. Journal of Comparative Physiology B: Biochemical, Systemic, and Environmental Physiology 279: 2299-2308.

Rahman, S., and R. L. Burke. 2010. Evaluating nest protectors for turtle conservation. Pages 1-23 in Final Reports of the Tibor T. Polgar Fellowship Program, 2009. Edited by D. J. Yozzo, S. H. Fernald, and H. Andreko. Hudson River Foundation New York, New York, USA.

Riley, J. L., and J. D. Litzgus. 2013. Evaluation of predatorexclusion cages used in turtle conservation: cost-analysis, and effects on nest environment and proxies of hatchling fitness. Wildlife Research 40: 499-511.

Ritchie, E. G., and C. N. Johnson. 2009. Predator interactions, mesopredator release, and biodiversity conservation. Ecology Letters 12: 982-998.

Robinson, C., and J. R. Bider. 1988. Nesting synchrony: a strategy to decrease predation of snapping turtle (Chelydra serpentina) nests. Journal of Herpetology 22: 470-463.

Rollinson, N., and R. J. Brooks. 2007. Marking nests increases the frequency of nest depredation in a northern 
population of painted turtles (Chrysemys picta). Journal of Herpetology 41: 174-176.

Samson, J., E. J. Hughes, and R. J. Brooks. 2007. Excavation is a nondeleterious method for obtaining fecundity and morphometric data from small-sized eggs of freshwater turtles. Chelonian Conservation and Biology 6: 255259 .

Schwarzkopf, L., and R. J. Brooks. 1985. Sex determination in northern painted turtles: effect of incubation at constant and fluctuating temperatures. Canadian Journal of Zoology 63: 2543-2547.

Seburn, D. 2007. Recovery strategy for species at risk turtles in Ontario. Ontario Multi-Species Turtles at Risk Recovery Team, Ottawa, Ontario, Canada, 72 pages.

Snow, J. E. 1982. Predation on painted turtle nests: nest survival as a function of nest age. Canadian Journal of Zoology 60: 3290-3292.

Spencer, R. J. 2002. Experimentally testing nest site selection: fitness trade-offs and predation risk in turtles. Ecology 83 : 2136-2144.

Spinks, P. Q., G. B. Pauly, J. J. Crayon, and H. B. Shaffer. 2003. Survival of the western pond turtle (Emys marmorata) in an urban California environment. Biological Conservation 113: 257-267.

Spotila, J. R. 2011. Saving Sea Turtles: Extraordinary Stories from the Battle Against Extinction. Johns Hopkins University Press, Baltimore, Maryland.
Storey, K. B., J. M. Storey, S. P. J. Brooks, T. A. Churchill, and R. J. Brooks. 1988. Hatchling turtles survive freezing during winter hibernation. Proceedings of the National Academy of Sciences 85: 8350-8354.

Strickland, J., P. Colbert, and F. J. Janzen. 2010. Experimental analysis of effects of markers and habitat structure on predation of turtle nests. Journal of Herpetology 44: 467-470.

Tinkle, D. W., J. D. Congdon, and P. C. Rosen. 1981. Nesting frequency and success: implications for the demography of painted turtles. Ecology 62: 1426-1432.

Tomillo, P. S., V. S. Saba, R. Piedra, F. V. Paladino, and J. R. Spotila. 2008. Effects of illegal harvest of eggs on the population decline of leatherback turtles in Las Baulas Marine National Park, Costa Rica. Conservation Biology 22: $1216-1224$.

Wirsing, A. J., J. R. Phillips, M. E. Obbard, and D. L. Murray. 2012. Incidental nest predation in freshwater turtles: inter- and intraspecific differences in vulnerability are explained by relative crypsis. Oecologia 168: 977-988.

Yntema, C. L. 1964. Procurement and use of turtle embryos for experimental procedures. The Anatomical Record 149: $577-585$.

Received 11 January 2014

Accepted 25 January 2014 